\title{
Cultural adaptation and reproducibility of the Measure Yourself Medical Outcome Profile (Mymop2)
}

\author{
Adaptação cultural e reprodutibilidade do Measure \\ Yourself Medical Outcome Profile (Mymop2)
}

\author{
Paula Monique Barbosa Lima ${ }^{[a]}$, Rosinete Fernandes de Brito ${ }^{[b]}$, \\ Rebeca Taciana Fernandes de Brito Farias ${ }^{[b]}$, Giselle Souza de Paiva ${ }^{[c]}$, Fabiano Timbó Barbosa ${ }^{[a]}$, \\ Célio Fernando de Sousa Rodrigues ${ }^{[a]}$, Patricia Nobre Calheiros da Silva ${ }^{[b] *}$ \\ [a] Universidade Federal de Alagoas (UFAL), Maceió, AL, Brazil \\ [b] Sociedade Brasileira de Terapia Intensiva (SOBRATI), Maceió, AL, Brazil \\ [c] Universidade Federal de Pernambuco (UFPE), Recife, PE, Brazil
}

\section{Abstract

\footnotetext{
*PMBL: Specialist, e-mail: ftpaulamonique@hotmail.com RFB: MSc, e-mail: rosineteft@hotmail.com RTFBF: Speciallist, e-mail: beca_mcz@hotmail.com GSP: MSc, e-mail: giselle.spaiva@yahoo.com.br FTB: PhD, e-mail: fabianotimbo@yahoo.com.br CFSR: PhD, e-mail: celiofernando@yahoo.com.br PNCS: MSc, e-mail: patynobre@yahoo.com.br
}

Introduction: The Measure Yourself Medical Outcome Pro囚le (MYMOP 2) is being used as a generic tool to document its effectiveness, together with the evaluation of health systems and their interventions. Objective: To assess the cultural adaptation and reproducibility of the Measure Yourself Medical Outcome Pro囚le (MYMOP2) questionnaire in a sample of patients undergoing cardiac surgery. Methods: The study sample consisted of 50 patients undergoing cardiac surgery for myocardial and valve revascularization, which were recruited from the cardiac ICU of a private hospital in Maceió, Alagoas. The MYMOP2 questionnaire was initially translated into Brazilian Portuguese. Cultural and conceptual adaptation were performed, so that patients were able to understand 
questions. All patients answered this instrument twice, on the same day, with two different interviewers, with an interval of 30 minutes between the interviews. After one day, the questionnaire was repeated on a second visit. This process was carried out with MYMOP and MYMOP2 FOLLOW UP. Reproducibility and validity were tested. Results: Cultural adaptations were made, so that the final version was obtained. Spearman correlation coefficient for MYMOP2 was 1 and FOLLOW UP was $0.794, p<0.001$. There were moderate correlations with the domains of the EQ-5D. MYMOP2 was validated and supported by a significant correlation between change scores and MYMOP2 change scores and the ability to detect an improvement in acute conditions. Conclusion: MYMOP2 questionnaire is reproducible, easy to understand and quick to apply. It should be included and used in any Brazilian study with the objective to assess disease impact over time.

Keywords: Thoracic surgery. Quality of life. Cultural adaptation.

\section{Resumo}

Introdução: O Measure Yourself Medical Outcome Profile (MYMOP2) está sendo usado como um instrumento genérico para documentar sua eficácia, juntamente com avaliação dos sistemas de saúde e suas intervenções Objetivo: Avaliar a adaptação cultural e reprodutibilidade do questionário em uma amostra de pacientes submetidos à cirurgia cardíaca. Método: A amostra constou de 50 pacientes submetidos à cirurgia cardíaca, recrutados na UTI Cardíaca de um hospital particular em Maceió-AL. Todos os pacientes responderam duas vezes a este instrumento, no mesmo dia, com dois entrevistadores distintos, com intervalo de 30 minutos de uma entrevista para a outra. Depois de um dia, a aplicação do questionário foi repetida numa segunda visita. Este processo foi realizado com o MYMOP2 e com o MYMOP2 FOLLOW UP. Foram testadas a reprodutibilidade e validade dos mesmos. Resultados: Foram feitas as adaptações culturais até ser obtida a versão final. $O$ coeficiente de correlação de Spearman para o MYMOP 2 foi de 1 e o FOLLOW UP foi de 0,794, com p<0,001. Houve correlações moderadas com os domínios do EQ-5D. O MYMOP2 foi validado apoiado pela correlação significativa entre o escore de mudança e a mudança na pontuação MYMOP2 e a capacidade deste instrumento para detectar uma melhora em condições agudas. Conclusão: O questionário MYMOP2 é reprodutível, de fácil compreensão e rápida aplicação, devendo ser incluído e utilizado em qualquer estudo brasileiro em que se queira avaliar o impacto das doenças ao longo do tempo.

Palavras-chave:Cirurgia cardíaca. Qualidade de vida. Adaptação cultural.

\section{Introduction}

Coronary Artery Disease (CAD) is one of the leading causes of death worldwide, and it is the first cause in the population aged 60 years or older. The incidence is increasing in developing countries (1). Although more successful percutaneous transluminal coronary angioplasty has been observed lately (2), the patients selected for cardiac surgery have become more severe, usually with low left ventricular function, making the postoperative (PO) stage more laborious and increasing mortality (3).

Median sternotomy is the predominant chest incision performed (4). Pulmonary complications have been described by several authors as the major cause of morbidity in the postoperative stage (3). Pain remains a challenge and needs to be better studied (5), as it has been a frequent complaint, motivated by causes such as cardiopulmonary bypass (CPB), general anesthesia, the surgical procedure itself, and pleural drains. It has contributed to the installation of pulmonary complications, which hinder the role of physical therapy and early mobilization in bed, leading to poor quality of life (QoL) $(4,6,7)$.

Quality of life is a subjective and multi-factorial concept, defined by physio-pathological, psycho-emotional, social, economic, cultural and even spiritual influences that people receive throughout their life (8), with the quantification of the impact of the disease on the activities of daily living and the wellbeing of patients being in a formal and standardized manner (9).

The questionnaires on Health-Related Quality of Life (HRQOL) aim to transform subjective feelings into objective data that can lead individuals to a condition of bad health $(10,11)$. They allow to determine the effectiveness of healthcare interventions 
and assist in the targeting of preventive measures, as well as measuring the overall impact of diseases (1215). To this end, appropriate instruments should be used after undergoing a rigorous validation process $(16,17)$ and having been recognized as a significant area of scientific knowledge in the health field (18). In this kind of study, the use of QoL measures that are valid, reliable and sensitive to clinical changes caused by the treatment is essential (11).

There are two types of questionnaires: generic and specific (19). The Measure Yourself Medical Outcome Profile (MYMOP2) is being used as a generic instrument to document its effectiveness (20), along with the evaluation of health systems and their interventions (21). The objectives, effects and values of treatment are prioritized and should allow for an unambiguous assessment for change over time (22).

The effects of the treatment were quantified using the MYMOP2 and encompassed into five themes: the importance of avoiding or reducing medication, symptom reduction, reduced functional capacity, improved physician-patient relationship, gain in control and improvement of skills and support with safety to patients (23).

From these themes, we seek to understand what patients consider as the most important symptoms and what brings harm to their physical activity, by evaluating the results on which the patient considers to be the most important for themselves. With this purpose, Charlotte Paterson developed, in 1996, the MYMOP (24), and it was revised to MYMOP2 after a second validation, in 1999. This time it included another section related to medications (23). Nevertheless, there is still a shortage of questionnaires described in Portuguese and adapted for the Brazilian culture, where one can quantify the clinical data reported by the patients themselves.

Thus, the aim of this study was to adapt this instrument to the Brazilian culture and evaluate the reproducibility of MYMOP2 in patients undergoing cardiac surgery.

\section{Methods}

The research proposal was approved by the Research Ethics Committee of the State University of Health Sciences of Alagoas (UNCISAL), Maceió, Alagoas, under protocol number 930 . A cross-sectional study was carried out at the Santa Casa de Misericórdia Hospital in Maceió, from June 2010 to April 2011. After being recruited and agreeing to participate in the research, the internal patients signed an Informed Consent Form.

\section{Sample}

The sample was calculated with 50 patients undergoing cardiac surgery. Considering the basis for calculation of other reproducibility studies, which were carried out with 30 patients, 50 were chosen for convenience, considering losses and more reliability.

Thus, the sample consisted of 58 patients, with eight in the cultural adaptation phase and 50 in the reproducibility phase. The study included patients undergoing cardiac surgery in the Cardiac ICU of a private hospital in Maceió, Alagoas, by means of a median sternotomy, using a CPB, mediastinal drain, extubated, aged between 40 and 60 years and presenting good cognitive skills.

Subjects were excluded if they presented infection and/or local inflammation, hemodynamic instability on the assessment day, patients using intra-aortic balloon or neurological sequelae of a central and/or peripheral nature and cognitive changes. Also, those who did not agree to sequential interviews, the visually impaired, people with other chronic disabling diseases, vulnerable individuals, such as Indians, pregnant women, and/or prison inmates did not participate in the study.

\section{Cultural adaptation of the questionnaire}

The questionnaire was translated into Portuguese by a native with command of the English language. This first version underwent cultural adaptation together with the committee of experts, who carried out the necessary adjustments. Then, this version was administered to eight patients and the response time, doubts and difficulties were noted. A new version was developed, in Portuguese, with the adjustments made with the patients, and it was translated into English by a second translator, with command of the English language.

The final English version was compared to the original version by the committee, to ensure that the original meaning had not been modified. This English version was sent to the authors of the original questionnaire, so they could assess whether this version 
had the same properties as the original questionnaire. The judging committee was composed of a specialist with command in the subject and in the questionnaire survey area, with command in both languages, the author of this research and the author of the questionnaire in its original version, allowing the adaptation of the questionnaire without changing its essence.

\section{Reproducibility}

The final adjusted version of the questionnaire was applied to 50 patients undergoing cardiac surgery, in two stages, with an interval of one day, and it was carried out by the same observer for the analysis of intra-observer reproducibility.

\section{Description of the MYMOP2 questionnaire}

MYMOP2 (Annex I) is a generic QoL questionnaire for acute or chronic diseases, assessing patients over time. This is a self-assessment questionnaire, composed and developed to assess symptoms and functional status, which should be completed the first time alone or with some private help. Patients choose one or two symptoms which they are seeking help for and which they consider to be the most important. Thus, Symptom 1 is the most important for the patients, mentioned in their own words. They should avoid the interpretation of the researcher, put it in their words or diagnose them. Symptom 2 is optional and is part of the same problem as Symptom 1 , without repeating it, and it should be encouraged. In the present study, Symptom 2 is found to be related to heart surgery.

The patient also chooses one activity of daily living, which is limited or hindered by this problem, which should always be something important to them, such as not being able to brush their hair, or going out to enjoy a meal. The choice of this activity is optional, but it should be encouraged.

These choices are recorded using the patients' words and the severity scores are recorded using a scale of zero to six points, where 0 would be absence of symptoms and 6 the unbearable limit of that symptom, or limitation of such activity, i.e., greater intensity of the complaint. Finally, wellbeing is scored on a similar scale, reporting how the patient evaluates the last seven days using the same 0-6 score. It must be emphasized that, in the first evaluation, when the patient mentions a symptom, this will never have a zero score, because by doing so would characterize the absence of this symptom.

The MYMOP profile is the average of the sum of all the recorded scores, providing an overall notion within the symptoms, activities and wellbeing, and its calculation is proportional to each response from the patient, since symptom 2 and the activities are optional. Patients can be monitored at any time by using a second questionnaire, that is the MYMOP2 FOLLOW UP (Annex II).

\section{Additional data}

Besides MYMOP2 and the FOLLOW UP, data were also collected on the HAD (25) (Annex III), EQ-5D (26) (Annex IV), Mini-Mental State Examination (27) (Annex V) and socioeconomic classification (28) (Annex VI).

The HAD questionnaire evaluates the level of anxiety and depression, where scores between 0-7 points do not characterize depression or anxiety; scores above these reflect increasing levels of depression and anxiety, with greater severity.

EQ-5D is a generic descriptive questionnaire in five areas, namely: mobility, care, usual activities, anxiety and depression, pain and discomfort; where the higher the score, the worse the patient's quality of life. It is a visual analog scale, where 0 is the worst state of health imaginable and 100 the best state of health imaginable, but, in this study, only the descriptive domains were used to resemble the generic SF-36 questionnaire, with which this questionnaire, in the original version, was compared. Thus, EQ-5D was chosen due to its responsiveness and for being generic, following the same line of reasoning for the validity of MYMOP2 from the University of Bristol in the UK.

The Mini-Mental is a scale that evaluates the patient's cognitive ability for the necessary response perception. The final score is the sum of the points, and it is considered normal above 24 . The socioeconomic classification evaluates the condition of the individual's instruction and possession, which goes from $\mathrm{A} 1$ (the best condition of the individual) to $\mathrm{E}$, the worst condition of the individual.

Statistical analysis 
Data were collected in a standardized form, encrypted to ensure confidentiality of the sample. All data were stored in an electronic data sheet (SPSS), and the calculations were made with the help of the SPSS statistical application version 13.0.

For descriptive statistical analysis, measures for central tendency were carried out, such as means and standard deviations. The Spearman correlation coefficient was applied for the reproducibility of MYMOP2 and FOLLOW UP, considering a strong correlation > 0.7 . To compare the distribution of the scores, the non-parametric Wilcoxon test was used, adopting the significance level of $5 \%(\mathrm{p}<0.05)$. Internal consistency was assessed with Cronbach's alpha, with $>0.7$ being considered a strong reliability. For the correlation of symptoms, wellbeing, activities and MYMOP2 profile between day 1 and the second day, the simple paired correlation was used and the for correlation between them, the Spearman correlation was used. The Mann-Withney test was used for the correlation between MYMOP2 and the overall quality of life questionnaire (Euroquol).

\section{Results}

We evaluated 74 patients undergoing cardiac surgery, with eight for the cultural adaptation, where 5 were men (62.5\%) and 3 women (37.5\%), and 66 for the reproducibility study. Sixteen patients from the reproducibility stage were excluded, for the following reasons: nine because they had undergone surgery that was not bypass or valve, four for presenting hemodynamic instability, one for having a state of mental confusion, and two for not having participated in the FOLLOW UP. Thus, 50 patients were considered to evaluate reproducibility.

Within this group for reproducibility, the majority had the disease for a period ranging from 1 to 5 years, with a mean ejection fraction (EF) of $64 \%( \pm 0.070)$, where $42(84 \%)$ were receiving drug treatment and $8(16 \%)$ did not use any medication. A significant part $(46 \%)$ reported that the medication had beneficial effects to their problem. The types of heart surgery were myocardial revascularization (52\%) and valvular (48\%), with sternotomy being the type of incision used for all with mediastinal drain. A total of $26(52 \%)$ were male, with a mean age of 54.22 ( \pm 6.30 ) years, belonging to, on average, social class $C$, with good cognitive ability, and without anxiety and depression. The average response time was $4.11 \mathrm{~min}$ utes $( \pm 1.38)$ and 3.6 minutes $( \pm 1.23)$, for MYMOP2 and FOLLOW UP respectively.

Because it is a simple questionnaire, there was no difficulty in translating it, becoming easily understood when applied to patients. The following is a description of the symptoms mentioned by patients, with symptom 1 being the most important to them. It was found that some people do not know what "symptom" means and they understood when the word complaint was used. They were encouraged to use their own words, avoiding our interpretation, using our words or diagnosis, which explained the complaint swelling, instead of edema, and fatigue, rather than dyspnea.

During the cultural adaptation, another difficulty was found with respect to the score of the complaints mentioned by the patient. For example, the complaint was pain, when they were asked to attribute a score of 1-6, they did not understand when the term was used at the extremes of the evaluation score, since the question was asked as follows: one for "as good as it could be" and six for "as bad as it could be", because zero monitoring means that the symptoms disappeared, it was observed that patients did not understand much about our questions. When the score of 1 to 6 was used, with one being for bearable and six unbearable, the patient quickly attributed a score, where zero remained for the disappearance of the symptom. This could never appear in MYMOP2 because, if there was a complaint, it would have to have a score of at least 1 , which was considered mild or bearable, while for the FOLLOW UP, if the symptoms were gone the score would be zero.

From there, these terms have been adapted from bearable to unbearable, because they are adjectives often used in our environment, making it easy to understand and making the application of the questionnaire more responsive for objective responses, and with quantification with respect to the intensity of their complaints. It was explained that in the range of 1 to 6 , the higher the numerical ladder, the worse the complaint cited by the patient would be, until the limit of 6 , making it unbearable. Thus, the following format was obtained: 0 - none; 1 - bearable; 2 - a little; 3 - average; 4 - a lot; 5 intense; 6 - unbearable.

After the cultural adaptation stage, we moved to reproducibility, where 50 individuals answered the 
questionnaire on two occasions, one with MYMOP2 on the first day and another with FOLLOW UP. Comparing the scores between visit one and visit two, we can see an excellent monitoring of response by the scores in Table 1.

The internal consistency of MYMOP2 was assessed with Cronbach's alpha coefficient, analyzing symptom 1 and 2 between the first and second day, where Cronbach's alpha coefficient indicates that the reliability of the questionnaire is moderate (Table 2). There was a statistically significant difference between the distribution of the scores for symptoms 1 and 2 between the first and the second day $(p<0.001)$.

Table 1 - Description of the mean results for MYMOP2 and FOLLOW UP in patients undergoing heart surgery

\begin{tabular}{lcc}
\hline $\begin{array}{c}\text { MYMOP2 } \\
\text { Categories }\end{array}$ & $\begin{array}{c}\text { MYMOP2 } \\
\text { Values } \\
\text { Day 1 }\end{array}$ & $\begin{array}{c}\text { MYMOP2 FOLLOW UP } \\
\text { Values } \\
\text { Day 2 }\end{array}$ \\
\cline { 2 - 3 } & Mean (SD) & Mean (SD) \\
\hline $\begin{array}{l}\text { Symptom 1 } \\
\mathbf{n = 5 0}\end{array}$ & $3.88(1.480)$ & $1.76(1.153)$ \\
$\begin{array}{l}\text { Symptom 2 } \\
\mathbf{n}=\mathbf{5 0}\end{array}$ & $3.87(1.408)$ & $2.13(1.565)$ \\
$\begin{array}{l}\text { Activity } \\
\mathbf{n}=\mathbf{3 0} \\
\begin{array}{l}\text { Wellbeing } \\
\mathbf{n}=\mathbf{5 0}\end{array}\end{array}$ & $3.57(1.278)$ & $3.03(1.159)$ \\
$\begin{array}{l}\text { MYMOP } \\
\text { Profile }\end{array}$ & $3.40(1.807)$ & $2.16(1.376)$ \\
\hline
\end{tabular}

Source: Research data

Note: $\mathrm{n}=$ sample number; $(\%)=$ frequency; $\mathrm{IC}=$ Confidence interval $95 \%$

Table 2 - Internal consistency of the MYMOP2 items, analyzing symptoms 1 and 2 between the first and second day

MYMOP2 Items Cronbach's Alpha of item

\begin{tabular}{ll}
\hline Symptom1_1_Day & 0.379 \\
Symptom1_2_Day & 0.620 \\
Symptom2_1_Day & 0.609 \\
Symptom2_2_Day & 0.582 \\
\hline
\end{tabular}

Thus, the incidence of symptom 1 was: pain (88\%), cough $(6 \%)$, fatigue $(2 \%)$, swelling $(2 \%)$, insomnia (2\%). As regards symptom 2, even though optional, the responses were: no symptom (38\%), pain (14\%), cough $(12 \%)$, malaise $(6 \%)$, fatigue $(12 \%)$, vomiting $(6 \%)$, secretions (4\%), high blood pressure (2\%), insomnia (2\%), swelling (4\%). The assessment of physical activity was optional, but, according to guidance from the questionnaire administration, it should be encouraged. Participants chose an activity of daily living that symptoms 1 and 2 prevented or interfered with. For being in bed during the postoperative period, $60 \%$ reported that they could not mobilize themselves in bed and, $40 \%$ that symptoms 1 and 2 did not interfere with their mobility or prevented them from performing another activity such as those in daily life, which interfered in their perception of well-being.

In the FOLLOW UP, when considering the appearance of a new symptom (symptom 3), one third of patients cited a new complaint, and, again, repeated the complaint of pain in some cases.

There was excellent reproducibility for MYMOP2, where its correlation coefficient was 1 and for FOLLOW UP it was 0.794 ( $p<0.001$, Spearman correlation coefficient). A positive correlation, moderate to strong, was detected in all MYMOP2 items and the MYMOP profile, as well as moderate correlation in most of the variables among the MYMOP2 and FOLLOW UP items with EQ-5D, which can be seen in tables 3 and 4 with the data relating to the criterion validity analysis.

Table 3 - Correlation among MYMOP2 items with the main symptom (symptom 1) and the MYMOP profile

\begin{tabular}{|c|c|c|}
\hline MYMOP2 Items & Symptoml (dayl) & MYMOP Profil \\
\hline Symptom 1 (day 2) & $0.565^{\star \star}$ & $0.519^{* *}$ \\
\hline Symptom 2 (day1) & $0.430^{*}$ & $0.645^{\star \star}$ \\
\hline Wellbeing (day 1) & 0.192 & $0.704^{* *}$ \\
\hline Activities (day 1) & -0.133 & $0.572^{\star *}$ \\
\hline MYMOP Profile & $0.658^{* \star}$ & 1.000 \\
\hline
\end{tabular}


Table 4 - Correlation* of symptom 1, wellbeing, activity and MYMOP profile with the EQ-5D in patients undergoing cardiac surgery

\begin{tabular}{lcccc}
\hline \multicolumn{1}{r}{ EQ-5D domains } & Symptom $\mathbf{1}$ & Wellbeing & Activity & MYMOP 2 Profile \\
\hline Mobility & -0.598 & -0.689 & -0.777 & -0.487 \\
Care & -0.898 & -0.754 & -1.322 & -0.813 \\
Usual activities & -0.330 & -0.340 & -0.736 & -0.234 \\
Anxiety and depression & -0.196 & -1.357 & -0.722 & -0.660 \\
Pain and discomfort & -0.884 & -0.142 & -0.535 & -0.391 \\
\hline
\end{tabular}

Note:*Mann-Whitney $p<0.05$

\section{Discussion}

Most of the QoL questionnaires were developed in North America and parts of Europe, which requires a validation process before being used in other languages. The MYMOP2 and the FOLLOW UP questionnaires were developed to be used in any patient with acute or chronic diseases. They are easy to read and apply and feature quick interpretation.

It has been shown in this study that there was little need for cultural adaptations to the questionnaire, and it showed strong reproducibility, considering the MYMOP2 correlation coefficient of 1 and its FOLLOW UP of 0.79 , with $p<0.001$. Between the first and the second visit, the symptoms remained the same for all patients, modifying only the intensity thereof, where, over time, these patients improved their symptoms. Thus, we can infer that this questionnaire is of great value to the possibility of its use by all areas of health, having the advantage of quantifying the improvement or worsening of the patient within a short application time and now being adapted to Brazilian Portuguese.

In the study by Paterson (24), the first symptom, the activity, wellbeing, and the MYMOP profile scores all showed significantly greater improvement for acute conditions (symptoms present $<4$ weeks) than chronic conditions (symptom present for $>4$ weeks). This author found an average variation in symptom 1 , in four weeks, in patients with acute conditions of 1.94 ( \pm 2.14 ), and 1.23 ( \pm 1.72 ) for chronic conditions ( $\mathrm{p}=0.009$, Mann-Whitney test), corroborating the present study, which speaks of the intra-hospital symptom in postoperative cardiac surgery, which are acute symptoms of 1 week, with improved responses in their FOLLOW UP.

In this study, as regards the evaluation of physical activity, all patients were confined to bed. Of these, more than half reported feeling difficulty moving in bed, whether in sitting up, eating, raising their arms and legs or moving while bathing. The remaining patients had no physical limitations resulting from the surgery, because they considered the postoperative discomfort from bearable to natural, whether due to pain or simply bed rest, or they did not have any physical limitations.

Furthermore, in the study by Paterson (24), correlation was performed with SF-36, a generic questionnaire, where, within the total sample, it was observed that the correlation between the MYMOP2 scales and the SF-36 scales were significant and stronger for the wellbeing scale and the MYMOP profile. For symptom 1 , the correlation coefficients ranged from -0.08 to -0.24 , for activity from -0.16 to -0.31 , for wellbeing from -0.19 to -0.48 , and for profile from -0.24 to -0.45 . This was expected according to the inferences of the author, as SF-36 has questions related to the entire previous month. Thus, considering the greater response time of SF-36, and these response results, we sought a generic questionnaire with a shorter response time, the EQ-5D, where the best moderate to strong correlations were found in relation to the EQ-5D, and the MYMOP2 and FOLLOW UP domains.

In a study evaluating patients with acute exacerbations and chronic bronchitis, using the EQ-5D, MOS- 6 and MYMOP, the latter was more responsive than questionnaires with standardized answers and a response rate for those with minimal changes between visits (29). The MYMOP has also been successfully used to evaluate patients in several other clinical situations, such as acupuncture $(30,31)$, therapeutic massage in an Aboriginal community (32) and in the chiropractic treatment of patellar tendinopathy (24).

In another recent study using MYMOP and W-BQ12, it was demonstrated that MYMOP is sensitive to 
changes, and may be a useful tool for evaluating clinical alterations in patients presenting chiropractic problems with a variety of symptoms and clinical conditions (33). In the Chinese version of MYMOP2, a negative correlation between the scores of the MYMOP profile and all the scores of SF-36 was demonstrated, which equals our Brazilian version which obtained a negative correlation between the MYMOP profile and EQ-5D, similar generic questionnaires (34).

In the FOLLOW UP, when considering the appearance of a new symptom (symptom 3), one third of patients in the study cited a new complaint, and again repeated the complaint of pain in some cases. This may be due to the fact that the patients consider, for example, incisional pain to be different from back pain. The other symptoms were fatigue, vomiting, coughing and, new data showed constipation in two patients. The FOLLOW UP forms can be completed at any time interval, and can be sent by mail or completed on a subsequent visit. They must have chosen for the formulation, symptom 1 , symptom 2 and the activity described in MYMOP2, unchanged, before the score. Symptom 3 is optional and should be added if it is something important for the patient. It is noteworthy that the patients were prescribed medications according to their postoperative clinical history, and they all received standard pain medication orally, every 8 hours, and modified according to clinical assessment and the pain score for each one, after completion of the FOLLOW UP score.

Due to the great impact of pain on the lives of patients undergoing cardiac surgery, the healthcare professional should review and commit themselves to reducing the incidence of this symptom. To this end, the mini-sternotomy has been performed reducing the incidence of pain and shortening the hospital stay (35). In addition, new features have been used, such as the application of Transcutaneous Electrical Nerve Stimulation (TENS) in relieving postoperative pain of cardiac surgery, already proven in research at our service (36), and that should be part of routine care.

MYMOP2 is designed to measure changes in the person over time, and therefore should be validated and reproducible. MYMOP2 was recognized for its capacity to detect different levels of variation in relation to the change, supported by significant correlation between change scores and the change in MYMOP score, and to detect acute and chronic improvements and their correlation with SF-36, among others.

\section{Conclusion}

All patients cited symptom 1 as their main complaint for pain, with pain from surgery or incision being those which occurred for the most part of them. The pain caused by the drain, in the back, the chest and moving around, amounted to a smaller part. Other complaints were fatigue, swelling, insomnia and coughing. Symptom 2 was cited by most of these patients, including those who had not cited pain as symptom 1 (except one patient), cited it as symptom 2, among other symptoms, such as fatigue, swelling, insomnia, coughing and vomiting. Therefore, a smaller number of patients did not have a second complaint. One patient reported incisional pain as symptom 1 and repeated symptom 2 as back pain, which for them was totally different, at this time they made a compliment about the evaluation of the questionnaire by describing exactly what they felt at the time and in their own words.

This study used MYMOP2 and the FOLLOW UP, and successfully adapted them to the Brazilian Portuguese. This is a questionnaire centered on the patient, it is reliable, practical and responsive to changes, which evaluates what patients consider most important, with excellent reproducibility, moderate reliability and validity, and it should be included and used in any Brazilian study where one wants to assess the impact of diseases over time, always taking as a basis the objective of healing the sick, or reducing the symptoms with quality of life.

The results obtained from this study allow us to suggest the implementation of this protocol, which prioritizes the most humane treatment. In this period, in addition to careful history, the institution of educational moments becomes necessary, where one can prepare the patient for the critical postoperative period, either through conversation or even information at the bedside.

\section{Acknowledgements}

The authors would like to thank the author of this questionnaire, PhD Charlotte Paterson, from the Department of Social Medicine at Bristol University, in the UK, for the prior authorization and assistance to validate these questionnaires into Portuguese. 


\section{References}

1. World Health Organization (WHO). Global burden of coronary heart disease. In: Mackay J, Mensah G. Atlas of Heart Disease and Stroke [Internet]. 2004 [cited 2011 Sept 27]. Available from: http://www.who.int/ cardiovascular_diseases/resources/atlas/en.

2. Imle PC. Fisioterapia em Pacientes com Problemas Cardíacos, Torácicos ou Abdominais após Cirurgia ou Trauma. In: Irwin S, Tecklin JS. Fisioterapia Cardiopulmonar. 3 ed. São Paulo: Manole; 2003. p. 375-403.

3. Botelho APV, Lima MRS. Revascularização do Miocárdio. In: Pulz C, Guizilini S, Peres PAT. Fisioterapia em Cardiologia. 1 ed. São Paulo: Atheneu; 2006. p. 221-32.

4. Coimbra VRM, Rodrigues MVH, Nozawa E, Feltrim MIZ. Rotinas do Atendimento Fisioterapêutico no Pós-operatório de Cirurgia Cardíaca. In: Auler Júnior JOC, Oliveira SA. Pós-operatório de Cirurgia Torácica e Cardiovascular. 1 ed. Porto Alegre: Artmed; 2004. p. 174-82.

5. Arcêncio L, Souza MD, Bortolin BS, Fernandes ACM, Rodrigues AJ, Évora PRB. Cuidados pré e pós-operatórios em cirurgia cardiotorácica: uma abordagem fisioterapêutica. Rev Bras Cir Cardiovasc. 2008; 23(3):400-10.

6. Mükerrem Erdogan MA, Abdullah Erdogan MD, Nazmiye Erbil MA, Hanife (Kabukcu) Karakaya MD, Abid Demircan MD. Prospective, Randomized, Placebo-controlled Study of the Effect of TENS on postthoracotomy pain and pulmonary function. World J Surg. 2005; 29(12):1563-70.

7. Lima FVSO. Fisioterapia em Cirurgia Cardíaca. In: Sarmento GJV. Fisioterapia Respiratória no Paciente Crítico. 1 ed. São Paulo: Manole; 2005. p. 300-6.

8. World Health Organization (WHO). International Digest of health Legislation [Internet]. 1988 [cited 2011 Sept 27]. Avaiable from: http://apps.who.int/ idhl-rils/frame.cfm?language=english

9. Jones PW, Quirck FH, Baveystock CM. The St. George`s Respiratory Questionnaire. Respir Med. 1991; 85(Suppl B):25-31.

10. Spilker B. Introduction. In: Spilker B. Quality of life assessments in clinical trials. New York: Raven; 1990: 3-10.
11. Jones PW, Quirck FH, Baveystock CM, Litllejohns P. A self complete measure for chronic airflow limitation - The Saint George Respiratory Questionnaire. Am Rev Respir Dis. 1992; 145(6):1321-7.

12. Aguiar CCT, Vieira APGF, Carvalho AF, MontenegroJunior RM. Instrumentos de avaliação de qualidade de vida relacionada à saúde no diabetes melito. Arq Bras Endocrinol Metab. 2008; 52(6):931-9.

13. Ferreira LN. Utilidades, galys e medição da qualidade de vida. Rev Port Saúde Pública. 2003; 3:51-63.

14. Ferreira PL, Ferreira LN. A medição de preferências em saúde na população portuguesa. Rev Port Saúde Pública. 2006; 24(2):5-14.

15. Paterson C, Britten N. Acupuncture for People with Chronic Illness: Combining Qualitative and Quantitative Outcome Assesment. J Altern Complement Med. 2003; 9(5):671-81.

16. Pagani TCS, Pagani Junior CR. Instrumentos de avaliação de qualidade de vida relacionada à saúde. Ensaios e C. 2006; 1(1):32-7.

17. Velarde-Jurado E, Avila-Figueroa C. Evaluación de la calidad de vida. Salud Publica Mex. 2002; 44(4):349-61.

18. Carr AJ, Thompson PW, Kirwan JR. Quality of life measures. Br J Reumatol. 1996; 35(3):275-81.

19. Guyatt GH. A taxonomy of health status instruments. J Rheumatol. 1995; 22(6):1188-90.

20. Puchala C, Paul S, Kennedy C, Mehl-Madrona L. Using Traditional Spirituality to Reduce Domestic Violence Within Aboriginal Communities. J Altern Complement Med. 2010; 16(1):89-96.

21. Reilly D, Mercer SW, Bikker AP, Harrison T. Outcome related to impact on daily living: preliminary validation of the ORIDL instrument. BMC Health Serv Res. 2007; 7:139.

22. Paterson C, Britten N. Seeking the patient's perspective: a qualitative assessment of EuroQol, COOPWONCA charts and MYMOP. Qual Life Res. 2004; 13(5):871-81.

23. Paterson C, Britten N. In pursuit of patient-centred outcomes: a qualitative evaluation of MYMOP2, measure yourself medical outcome profile. J Health Serv Res Policy. 2000; 5(1):27-36. 
24. Paterson C. Measuring outcomes in primary care: a patient generated measure, MYMOP, compared with the SF-36 health survey. BMJ. 1996; 312:1016-20.

25. Marcolino JAM, Mathias LAST, Piccinini Filho L, Guaratini AA, Suzuki FM, Alli LAC. Escala Hospitalar de Ansiedade e Depressão: Estudo da Validade de Critério e da Confiabilidade com Pacientes no Pré-Operatório. Rev Bras Anestesiol. 2007; 57(1): 52-62.

26. Rabin R, et al. EQ-5D-5L User Guide: basic information on how to use the EQ-5D-5L instrument: version 1.0. Rotterdan: EuroQol Group, 2011. 25p.

27. Cockrell JR, Folstein MF, Copeland JRM, et al. Mini-Mental State Examination [Internet]. [cited 2011 Sept 28] Available from: http://www.minimental.com/.

28. ABIPEME (Associação Brasileira de Institutos de Pesquisa e Mercado). Classificação socioeconômica: critério ABIPEME [Internet]. 2003 [cited 2010 Apr 20]. Available from: http://www.ufrn.br/sites/fonaprace/ perfil_anexo3.doc.

29. Paterson C, Langan CE, McKaig GA, Anderson PM, Maclaine GDH, Rose LB, et al. Assessing patient outcomes in acute exacerbations of choric bronchitis: the measure you medical outcome (MYMOP2), medical outcomes study 6-item general health survey (MOS 6A) and EuroQol (EQ-5D). Qual Life Res. 2000; 9:521-7.

30. Fonnebo V, Grimsgaard S, Walach H, Ritenbaugh C, Norheim AJ, MacPherson $\mathrm{H}$, et al. Researching complementary and alternative treatments-the gatekeepers are not at home. BMC Med Res Methodol. 2007; 7:7.
31. Paterson C, Baarts C, Launso L, Verhoef MJ. Evaluating complex health interventions: a critical analysis of the'outcomes' concept. BMC Complementary and Alternative Medicine. 2009; 9:18.

32. Tang JL, Liu BY, Ma KW. Traditional Chinese medicine. Lancet. 2008; 372(9654):1938 - 40.

33. Polus BI, Kimpton AJ, Walsh MJ. Use of the measure your medical outcome profile (MYMOP2) and W-BQ12 (Well-Being) outcomes measures to evaluate chiropractic treatment: an observational study. Chiropr Man Therap.2011; 19:7.

34. Chung VCH, Wong VCW, Lau CH, Hui H, Lam TH, Zhong LX, et al. Using Chinese Version of MYMOP in Chinese Medicine Evaluation: Validity, Responsiveness and Minimally Important Change. Health Qual Life Outcomes. 2010; 8:111.

35. Guizilini S, Bolzan DW, Faresin SM, Alves FA, Gomes WJ. Miniesternotomia na cirurgia de revascularização miocárdica preserva função pulmonar pós-operatória. Arq. Bras. Cardiol. 2010; 95(5):587- 93.

36. Lima PMB, Farias RTFB. Avaliação da Estimulação Elétrica Nervosa Transcutânea sobre a dor e força muscular respiratória de pacientes submetidos à cirurgia de revascularização do miocárdio [TCC]. Maceió: Centro Universitário CESMAC; 2008.

Received: 10/14/2014 Recebido: 14/10/2014

Approved: 08/17/2015 Aprovado: 17/08/2015 


\section{ANNEX I - MYMOP 2}

\section{* MYMOP2 *}

Full name

Date of birth

Address and postcode

Today's date

Practitioner seen

Choose one or two symptoms (physical or mental) which bother you the most. Write them on the lines.

Now consider how bad each symptom is, over the last week, and score it by circling your chosen number.

As good as it
SYMPTOM 1:

Now choose one activity (physical, social or mental) that is important to you, and that your problem makes difficult or prevents you doing. Score how bad it has been in the last week.

$\begin{array}{llllllll}\text { ACTIVITY: } & 0 & 1 & 2 & 3 & 4 & 5 & 6 \\ & \begin{array}{l}\text { As good as it } \\ \text { could be }\end{array} & & & & \begin{array}{l}\text { As bad as it } \\ \text { could be }\end{array}\end{array}$

Lastly how would you rate your general feeling of wellbeing during the last week?

$\begin{array}{lllllll}0 & 1 & 2 & 3 & 4 & 5 & 6 \\ \begin{array}{l}\text { As good as it } \\ \text { could be }\end{array} & & & & & & \begin{array}{l}\text { As bad as it } \\ \text { could be }\end{array}\end{array}$

How long have you had Symptom 1, either all the time or on and off? Please circle:

0 - 4 weeks $\quad 4-12$ weeks 3 months -1 year $\quad 1-5$ years over 5 years

Are you taking any medication FOR THIS PROBLEM? Please circle: $\quad$ YES/NO

IF YES:

1. Please write in name of medication, and how much a day/week

2. Is cutting down this medication: Please circle:

Not important a bit important very important not applicable

IF NO:

Is avoiding medication for this problem:

Not important a bit important very important not applicable 


\section{ANNEX II - MYMOP 2 FOLLOW UP}

\section{* MYMOP2 Follow up *}

Full name

Today's date

Please circle the number to show how severe your problem has been IN THE LAST WEEK.

This should be YOUR opinion, no-one else's!

SYMPTOM $1:$

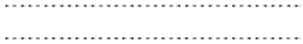

SYMPTOM 2

ACTIVITY

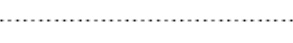

WELLBEING

How would you rate

your general feeling

of wellbeing?

As good as it
could be

could be

0
As good as it
could be

could be

As good as it
could be

could be

0
As good as it

could be
6

As bad as it could be

6

As bad as it could be

As bad as it could be

If an important new symptom has appeared please describe it and mark how bad it is below. Otherwise do not use this line.

SYMPTOM 3 :

As good as it
could be

6 As bad as it could be

The treatment you are receiving may not be the only thing affecting your problem. If there is anything else that you think is important, such as changes you have made yourself, or other things happening in your life, please write it here (write overleaf if you need more space):

Are you taking medication FOR THIS PROBLEM? Please circle: YES/NO IF YES:

Please write in name of medication, and how much a day / week 


\section{ANNEX III - ANXIETY AND DEPRESSION SCALE - HAD}

\section{ANXIETY AND DEPRESSION SCALE - HAD}

This questionnaire will help your doctor know how you are feeling. Read every sentence. Mark with an X the answer that best matches how you have been feeling during the LAST WEEK.

There is no need to think a lot about each question. In this questionnaire, spontaneous responses are more valuable than those that you think a lot about.

Choose only one answer for each question.

Name:

Age:

Profession:

Diagnosis:

\section{Education: Occupation:}

\section{Marital Status:}

Date:

\section{I feel tense or uptight:}
( ) Most of the time
( ) A lot of the time
( ) Sometimes
( ) Never

\section{I still like the same things as before:}
( ) Yes, just like before
( ) Not as much as before
( ) Just a little
( ) I still cannot seem to enjoy anything

\section{I feel a kind of fear, as if something bad were going to happen}
( ) Yes, and in a very strong way
( ) Yes, but not so strong
( ) A little, but it does not worry me
( ) I do not feel anything like that

\section{I laugh and enjoy myself when I see funny things}
( ) The same way as before
( ) Currently a little less
( ) Currently a lot less
( ) I cannot any more

\section{I have got a head full of worries}
( ) Most of the time
( ) A lot of the time
( ) Sometimes
( ) Rarely 


\section{I feel happy \\ ( ) Never \\ ( ) Seldom \\ ( ) Often \\ ( ) Most of the time}

\section{I am able to sit at ease and feel relaxed}

( ) Yes, almost always

( ) Often

( ) Seldom

( ) Never

\section{I am slow at thinking about and doing things}

( ) Almost always

( ) Often

( ) Sometimes

( ) Never

I have a bad sense of fear, like the goose bumps or a tightness in the stomach
( ) Never
( ) Sometimes
( ) Often
( ) Almost always

I feel uneasy, like I could not stay still anywhere

( ) Yes, so much

( ) Quite a lot

( ) A little

( ) I do not feel like that

I fell excited about the good things to come

( ) The same way as before

( ) A little less than before

( ) A lot less than before

( ) Almost never

All of a sudden, I have a feeling of panic

( ) Almost all of the time

( ) Several times

( ) Sometimes

( ) I have not felt that

I can feel pleasure when I watch a good TV show, listen to the radio, or when I read something

( ) Almost always

( ) Several times

( ) Seldom

( ) Almost never
I have lost interest in my appearance
( ) Completely
( ) I am no longer taking care of myself like I should
( ) Perhaps not as much as before
( ) I take care of myself the same way as before 


\section{ANNEX IV - ANXIETY AND DEPRESSION SCALE - HAD}

EQ-5D Quality of life measurement (from the EuroQol group)

Descriptive classification of EuroQol (current version)

Mobility

I have no problem walking

I have some problems walking

I have to be in bed

\section{Personal care}

I have no problem taking care of myself

I have some problems washing and dressing myself

I am unable to wash or dress myself

Usual activities (e.g., work, studies, household chores, family or leisure activities)

I have no problem performing my usual activities

I have some problems performing my usual activities

I am unable to perform my usual activities

\section{Pain/malaise}

I have no pain or malaise

I have moderate pain or malaise

I have extreme pain or malaise

\section{Anxiety/depression}

I am not anxious or depressed

I am moderately anxious or depressed

I am extremely anxious or depressed

Source: Adapted from the Portuguese version of EuroQol (EuroQol Group, 2000). 


\title{
ANNEX V - ADAPTATION OF THE FOLSTEIN MINI-MENTAL STATE EXAMINATION
}

\author{
Adaptation of the Folstein Mini-Mental State Examination
}

\begin{tabular}{|c|c|}
\hline Adaptation of the Folstein Mini-Mental State Examination & TOTAL \\
\hline \multicolumn{2}{|l|}{$\begin{array}{l}\text { Date Orientation (what day is it today? Record the items omitted) } \\
\text { day ( ), month ( ), year ( ), day of the week ( ), morning / afternoon ( ) }\end{array}$} \\
\hline \multicolumn{2}{|l|}{$\begin{array}{l}\text { Place Orientation (where are you? ask the items omitted) } \\
\text { country ( ), state ( ), city ( ), place ( ), floor ( ) }\end{array}$} \\
\hline \multicolumn{2}{|l|}{$\begin{array}{l}\text { Registration of objects (name clearly and slowly three objects and ask the patient to repeat them) } \\
\text { window ( ), jacket ( ), watch ( ) }\end{array}$} \\
\hline \multicolumn{2}{|l|}{ 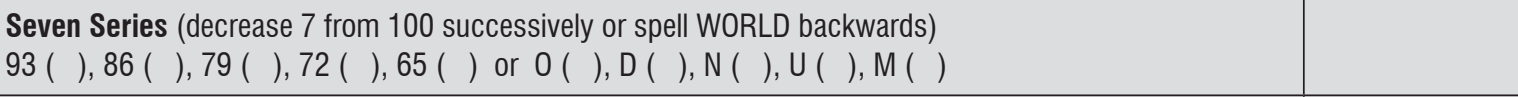 } \\
\hline \multicolumn{2}{|l|}{$\begin{array}{l}\text { Remember Objects (recall the three objects mentioned above) } \\
\text { window ( ), jacket ( ), watch ( ) }\end{array}$} \\
\hline \multicolumn{2}{|l|}{$\begin{array}{l}\text { Denomination (point at the watch and ask "What is this?". Repeat with a pencil) } \\
\text { watch ( ), pencil ( ) }\end{array}$} \\
\hline \multicolumn{2}{|l|}{$\begin{array}{l}\text { Repetition (repeat the phrase "Blacksmith's house, wooden skewer" or "neither here, nor there, nor there") } \\
\text { correct repetition on 1st try ( ) }\end{array}$} \\
\hline \multicolumn{2}{|l|}{$\begin{array}{l}\text { Verbal Command (take the piece of paper, fold it in half and place it on the table) } \\
\text { pick up the paper ( }) \text {, fold it in half ( }) \text {, place it on the table ( ) }\end{array}$} \\
\hline \multicolumn{2}{|l|}{$\begin{array}{l}\text { Written Command (show a piece of paper with the sentence "Close your eyes") } \\
\text { close your eyes ( ) }\end{array}$} \\
\hline \multicolumn{2}{|l|}{$\begin{array}{l}\text { Write (write a sentence) } \\
\text { Sentence with subject + verb and that makes sense ( ) }\end{array}$} \\
\hline \multicolumn{2}{|l|}{$\begin{array}{l}\text { Draw (copy the drawing of the intersection of } 2 \text { pentagons) } \\
\text { image with } 10 \text { corners and two intersecting lines ( ) }\end{array}$} \\
\hline TOTAL (maximum = 30) & \\
\hline
\end{tabular}
Interpretation:

Add a 1 point for each of the items ( ) answered correctly and register the total in the right-hand column. The final score is the sum of the points, and it is considered normal when more than 24. Bertolucci et al, 1994 applied the FMMS on 530 Brazilians with varying degrees of schooling and obtained the following cut-off points for normality: illiterate $=13 ; 1$ to 8 years schooling $=18$ and $>8$ years schooling $=26$ 


\section{ANNEX VI - SOCIO-ECONOMIC CLASSIFICATION}

\section{SOCIO-ECONOMIC CLASSIFICATION}

(Brazilian Society of Market Research, 1997)

\begin{tabular}{|c|c|c|c|c|c|}
\hline Possession of items & Does not have & Has & & & \\
\hline & & 1 & 2 & 3 & 4 or more \\
\hline Color TV & 0 & 2 & & & \\
\hline Radio & 0 & 1 & & & \\
\hline Bathroom & 0 & 2 & & & \\
\hline Automobile & 0 & 2 & & & \\
\hline Housemaid & 0 & 2 & & & \\
\hline Vacuum cleaner & 0 & 1 & & & \\
\hline Washing machine & 0 & 1 & & & \\
\hline Refrigerator & 0 & 2 & & & \\
\hline Video cassette or DVD & 0 & 2 & & & \\
\hline Freezer (independent and/or duplex appliance) & 0 & 1 & & & \\
\hline
\end{tabular}

\begin{tabular}{|l|c|}
\hline \multicolumn{1}{|c|}{$\begin{array}{c}\text { Level of education of the head of the } \\
\text { household }\end{array}$} & 0 \\
\hline Illiterate/Incomplete elementary & 1 \\
\hline Complete elementary/Incomplete junior high & 2 \\
\hline Complete junior high/Incomplete high school & 3 \\
\hline Complete high school/Incomplete university & 5 \\
\hline Complete university & \\
\hline
\end{tabular}

\begin{tabular}{|c|c|}
\hline Class A1: & $30-34$ points \\
\hline Class A2: & $05-29$ points \\
\hline Class B1: & $21-24$ points \\
\hline Class B2: & $17-20$ points \\
\hline Class C: & $11-16$ points \\
\hline Class D: & $6-10$ points \\
\hline Class E: & $0-5$ points \\
\hline
\end{tabular}

Number of points: 
